\title{
Computerised Tomography Findings of Abdominal Tuberculosis - A Must Know
}

Authors

\author{
Dr Subhasish Panda ${ }^{1}$, Dr. Subhashree Dash ${ }^{2 *}$, Dr Savitri Bhagat ${ }^{3}$, Dr B.B. Panda ${ }^{4}$ \\ P.G. Department of Radiodiagnosis, V.S.S. Institute of Medical Sciences and Research, Burla, Odisha, India \\ *Corresponding Author \\ Dr Subhashree Dash
}

\begin{abstract}
Introduction: Tuberculosis is a commonly prevalent disease in India owing to widespread overpopulation and malnutrition and has a rising trend due to the increasing incidence of HIV and use of immunosuppressive drugs. Although a great mimicker of several other diseases such as inflammatory bowel diseases, carcinoma and other infectious bowel diseases, ultrasonography and computed tomography are very useful in arriving at a confident diagnosis of abdominal tuberculosis.

Methods: This was an observational cross-sectional study conducted to evaluate the spectrum of abdominal tuberculosis using CT (computerised tomography). A total of forty six patients of abdominal tuberculosis were evaluated over a period of one year. The associated findings and complications produced by this disease were also evaluated. Isolated Genitourinary and solid organ involvement was excluded.

Results: Peritoneal involvement was the most common feature followed by affliction of gastrointestinal tract. Loss of mural stratification was most commonly seen. Extraabdominal findings of pulmonary involvement were predominant in these cases.

Conclusion: $C T$ findings along with laboratory and clinical findings can significantly help in diagnosis of abdominal tuberculosis.

Keywords: extrapulmonary, lymphadenopathy, necrotic, peritoneal, peritonitis, cocoon, ileocaecal, Crohn, intussusceptions.

Introduction

Even with the global pandemic grabbing all eyeballs, tuberculosis is a common potentially life threatening disease having a global burden of about 12 million. It can virtually affect any organ of the body. Although pulmonary, lymphatic, genitourinary forms of tuberculosis are most frequent, abdominal involvement is a common presentation of tuberculosis and may involve solid viscera like liver and spleen, pancreas, gastrointestinal tract, gall bladder, peritoneum and abdominal lymph nodes ${ }^{(1)}$.

Mycobacterium tuberculosis can reach
gastrointestinal tract by ingestion of infected sputum, the haematogenous route, contiguous spread from involved lymph nodes and the fallopian tubes ${ }^{(2)}$. Upon ingestion of sputum, acid fast bacillus accumulates in the Peyer's patches of terminal ileal region due to relative stagnation in that region resulting in ileocaecal tuberculosis. Mesentery and omentum can be affected by disseminated miliary tuberculosis of the bowel and the peritoneum and is thought to be caused by hematogenous spread or local spread from GI involvement (penetration of
\end{abstract}


involved bowel or lymph nodes draining into the peritoneum).

In abdominal $\mathrm{TB}$, peritoneal involvement is the most common form followed by gastrointestinal involvement. Although a great mimicker of several other entities such as inflammatory bowel disease and neoplasms, imaging findings are highly suggestive to arrive at a conclusive diagnosis along with corroboration of clinical features and laboratory findings. This study highlights the commonly encountered as well as some extremely rare manifestations of abdominal tuberculosis.

\section{Materials and Methods}

A total of 46 patients clinically diagnosed to be suffering from abdominal tuberculosis referred to the Postgraduate Department of Radiodiagnosis, VIMSAR, during July 2016 to Dec 2017 were included in this study. Non-contrast and contrast enhanced CT (oral plus intravenous and rectal when required) examination of patients were carried out using Siemens Somatom Emotion CT Scan machine. Confirmatory diagnosis of tubercular involvement of the abdomen was achieved by satisfactory fulfillment of at least one of the following criteria -

- Elevated Adenosine Deaminase (ADA) or $\mathrm{LDH}$ values in the peritoneal fluid

- Positive Polymerase Chain Reaction (PCR)

- Positive Culture of Ascitic Fluid

- Satisfactory Response to Antitubercular Therapy

Isolated solid organ involvement and genitourinary tuberculosis were excluded from the study.

\section{Results}

Out of the 46 patients enrolled in the study, 35 patients were radiographically diagnosed to be suffering from abdominal tuberculosis. Among them 21 were males $(60 \%)$ and 14 were females (40\%). The most common presenting clinical features was low-grade fever $(60 \%)$ followed by abdominal pain (50\%), abdominal distension, documented weight loss and constipation. Bowel involvement (small bowel in particular) was identified in 11 cases (31.4\%), with ileo-caecal region most commonly involved (Table 3 ).

The pattern of bowel involvement and CT enhancement findings are depicted in Table 4 and 5. An abdominal cocoon (now termed sclerosing encapsulated peritonitis) was found in two cases while a solitary case of jejuno-jejunal intussusception was also seen. Bowel obstruction was the most frequently found complication (Table 6). Peritoneal collection was the most common peritoneal finding (Table 7) and homogenous discrete lymph nodes were mostly observed (Table 7). Associated findings of pulmonary tuberculosis were seen in $40 \%$ of cases (Table 8 ).

Table 1. Tomographic Findings of Study Subjects

\begin{tabular}{|l|c|c|}
\hline Gross findings & No. of Patients & Percentage \\
\hline Peritoneal Involvement & 31 & 88.57 \\
\hline $\begin{array}{l}\text { Gastro-intestinal Tract } \\
\text { Involvement }\end{array}$ & 11 & 31.4 \\
\hline
\end{tabular}

*Please note that the numbers in above table are overlapping, due to the presence of both findings in multiple patients.

Table 2 Pattern of Peritoneal Involvement

\begin{tabular}{|c|c|c|}
\hline Pattern & $\begin{array}{c}\text { Number of } \\
\text { Patients }\end{array}$ & Percentage \\
\hline Peritoneal Collection & 17 & 48.57 \\
\hline $\begin{array}{l}\text { Peritoneal Thickening } \\
\text { (Smooth) } \\
\text { (Nodular) }\end{array}$ & 9 & $\begin{array}{l}25.71 \\
5.71\end{array}$ \\
\hline $\begin{array}{l}\text { Omental Thickening / } \\
\text { Caking }\end{array}$ & 4 & 11.4 \\
\hline $\begin{array}{l}\text { Mesenteric Stranding/ } \\
\text { Nodes }\end{array}$ & 17 & 48.57 \\
\hline Total & 31 & 88.57 \\
\hline
\end{tabular}

* Please note that the numbers in above table are overlapping, due to the presence of both findings in multiple patients.

Table 3 Bowel Loop Involved in the Patients

\begin{tabular}{|l|c|c|c|c|c|}
\hline $\begin{array}{l}\text { Site of Bowel } \\
\text { Loop }\end{array}$ & Focal & $\begin{array}{c}\text { Segment } \\
\text { al }\end{array}$ & $\begin{array}{c}\text { Diffu } \\
\text { se }\end{array}$ & $\begin{array}{c}\text { Tot } \\
\text { al }\end{array}$ & $\begin{array}{c}\text { Percenta } \\
\text { ge }\end{array}$ \\
\hline Stomach & 1 & - & - & - & 2.8 \\
\hline Jejunum & - & 1 & - & 1 & 2.8 \\
\hline Ileum & - & 1 & - & 1 & 2.8 \\
\hline Ileocaecal & - & 7 & - & 7 & 20 \\
\hline Ascending Colon & - & 1 & - & 1 & 2.8 \\
\hline Total & 1 & 10 & 0 & 11 & 31.4 \\
\hline
\end{tabular}


Table 4 Pattern of Bowel thickening

\begin{tabular}{|l|c|c|}
\hline Pattern of Involvement & $\begin{array}{c}\text { Number of } \\
\text { Patients }\end{array}$ & Percentage \\
\hline Symmetric Thickening & 6 & 54.5 \\
\hline Asymmetric Thickening & 5 & 45.4 \\
\hline
\end{tabular}

Table 5 Pattern of CT Enhancement of Bowel Loops

\begin{tabular}{|l|c|c|}
\hline Pattern of enhancement & $\begin{array}{c}\text { Number of } \\
\text { Patients }\end{array}$ & Percentage \\
\hline Mural stratification present & 3 & 27.2 \\
\hline Loss of mural stratification & 8 & 72.7 \\
\hline Mucosal hyperenhancement & 6 & 54.5 \\
\hline
\end{tabular}

Table 6 Complications of Bowel Tuberculosis

\begin{tabular}{|l|c|c|}
\hline Complication & $\begin{array}{c}\text { Number of } \\
\text { Patients }\end{array}$ & Percentage \\
\hline Perforation & 1 & 2.85 \\
\hline $\begin{array}{l}\text { Bowel obstruction } \\
\text { (Proximal dilatation) }\end{array}$ & 4 & 11.4 \\
\hline Intussusception & 1 & 2.85 \\
\hline Total & 5 & 14.2 \\
\hline
\end{tabular}

Table 7 Lymph Node Characteristics

\begin{tabular}{|l|c|c|c|}
\hline $\begin{array}{l}\text { Pattern of } \\
\text { Lymph } \\
\text { Nodes }\end{array}$ & \multicolumn{2}{|c|}{ Number of Patients } & $\begin{array}{c}\text { Percentage of } \\
\text { Lymphadenopathy }\end{array}$ \\
\cline { 2 - 3 } Necrotic & Enlarged & $\begin{array}{c}\text { Not } \\
\text { Enlarged }\end{array}$ & \\
\hline $\begin{array}{l}\text { Homogenous, } \\
\text { Discrete }\end{array}$ & 5 & - & 25 \\
\hline $\begin{array}{l}\text { Confluent } \\
\text { Matted }\end{array}$ & 7 & 2 & 43.7 \\
\hline Calcified & 2 & - & 11.7 \\
\hline Total & 14 & 1 & 6.2 \\
\hline
\end{tabular}

Table 8 Association with Other Sites

\begin{tabular}{|l|c|c|}
\hline Association & $\begin{array}{c}\text { Number of } \\
\text { Patients }\end{array}$ & Percentage \\
\hline Pulmonary Tuberculosis & 14 & 40 \\
\hline $\begin{array}{l}\text { Solid organ involvement } \\
\text { (Liver, Spleen, Pancreas) }\end{array}$ & 3 & 8.5 \\
\hline Psoas abscess & 2 & 5.7 \\
\hline Vertebral involvement & 3 & 8.5 \\
\hline
\end{tabular}

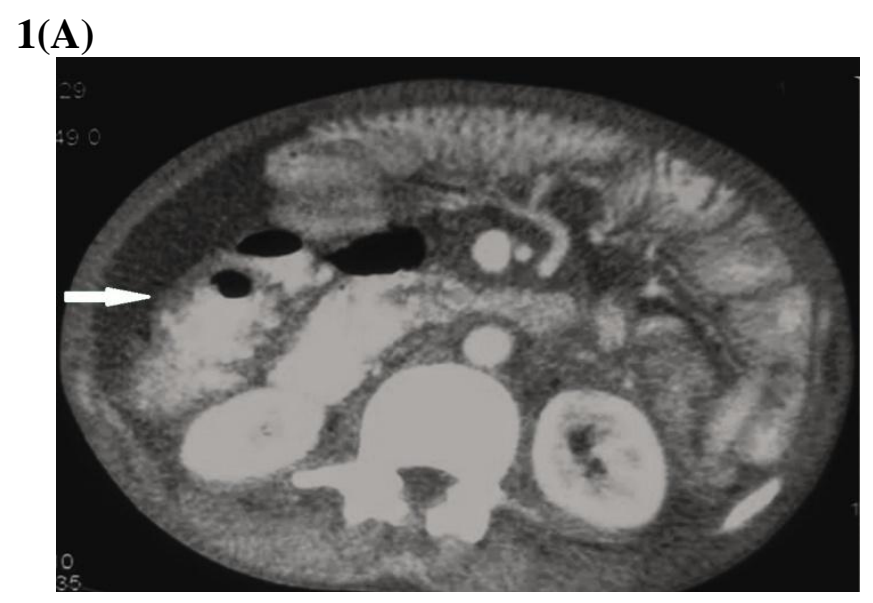

1(B)

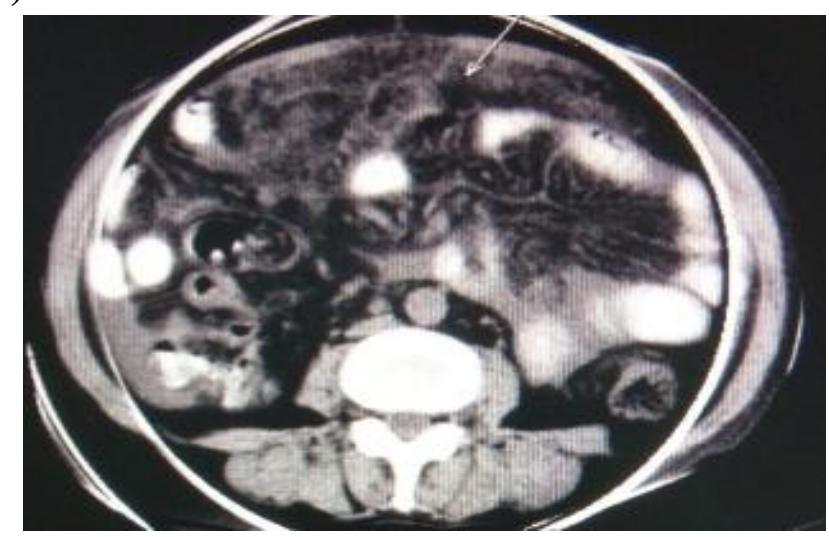

Fig 1 (A). Post contrast CT showing non enhancing peritoneal collection bounded by smoothly thickened enhancing parietal peritoneum (arrow). Fig 1 (B). CT showing omental stranding (arrow) and free hypodense fluid in peritoneum.

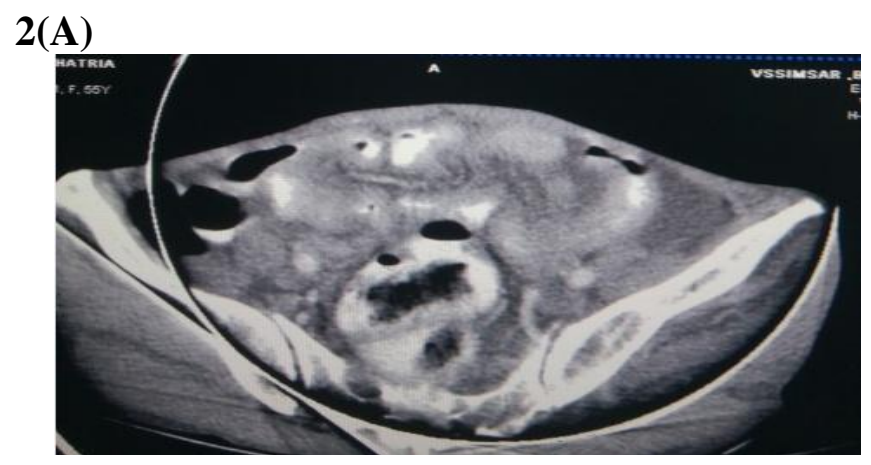

2(B)

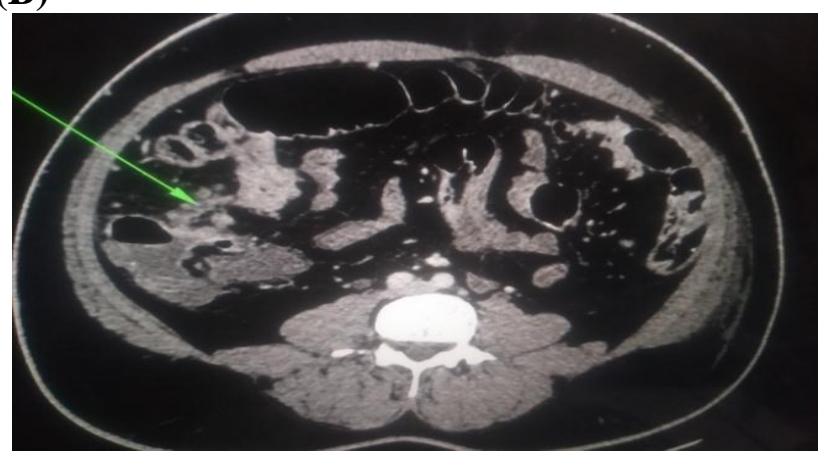

Fig 2(A). CT showing segmental symmetric thickening of ileal loops in iliac region, with hypodense peritoneal collection. Fig 2(B) depicts multiple lymph nodes located in close approximation in right iliac fossa (arrow) adjacent to thickened and narrowed ileocaecal valve. Also seen is proximal dilatation of distal ileum. 


\section{JMSCR VoI||08||Issue||07||Page 68-73||July}

3(A)

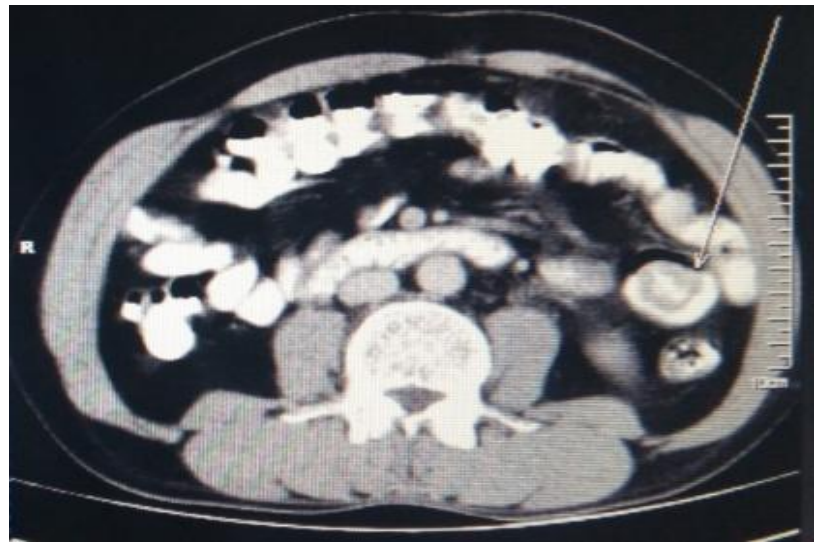

3(B)

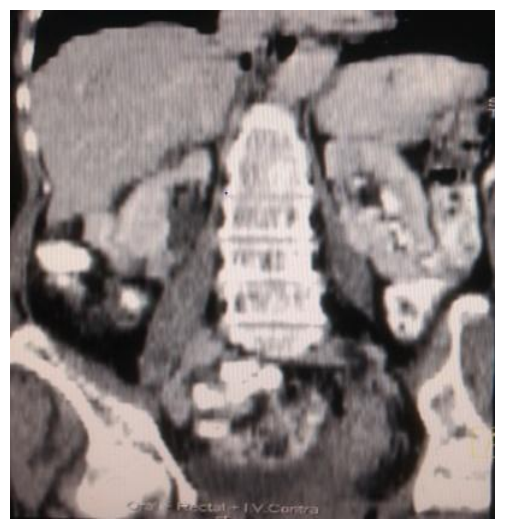

Fig 3 (A) Axial CT identifying a jejunojejunal intussusception (arrow) with mural thickening which resolved after Antitubercular therapy. Fig 3(B) Coronal CT showing caecal pull up in another patient.

4(A)

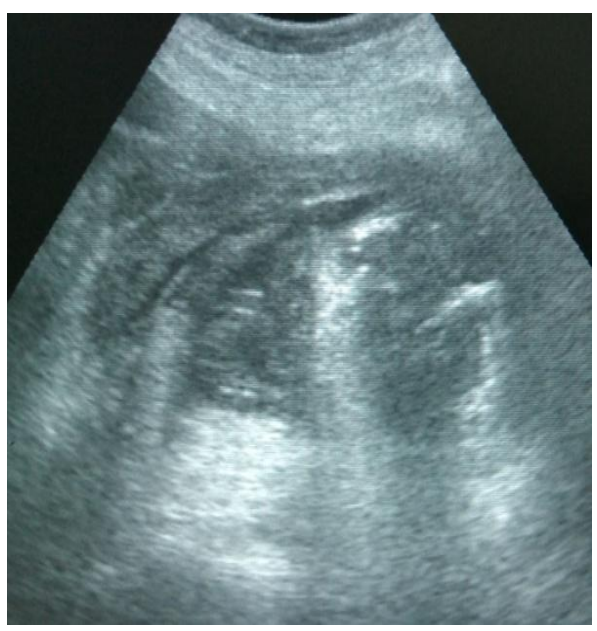

4(B)

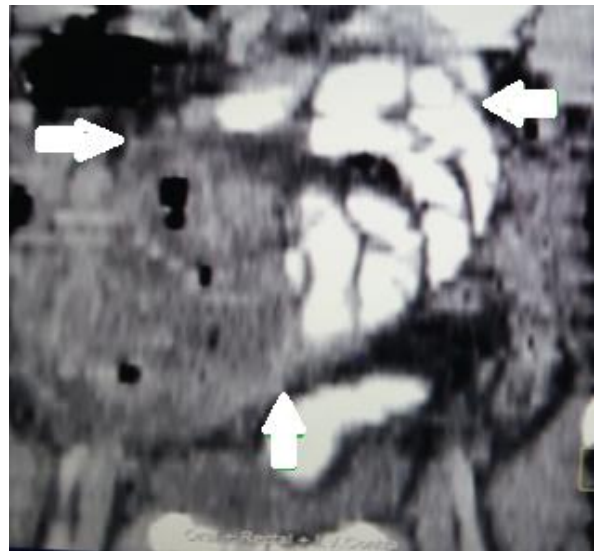

Fig 4 (A). USG image and Fig 4(B)- corresponding CT image showing congregation of small bowel loops in the center of abdomen with a fibrous membrane (thick arrows in b) surrounding the loops suggestive of Sclerosing Encapsulated Peritonitis.

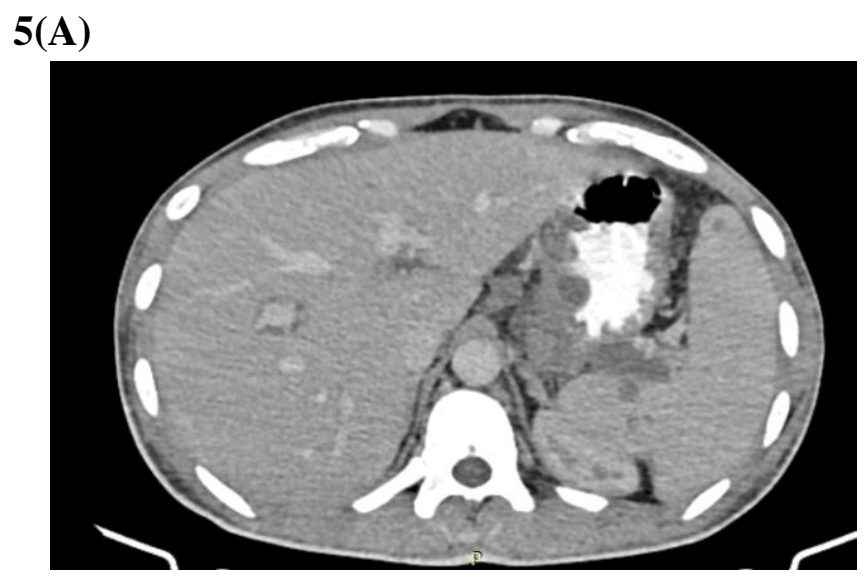

5(B)

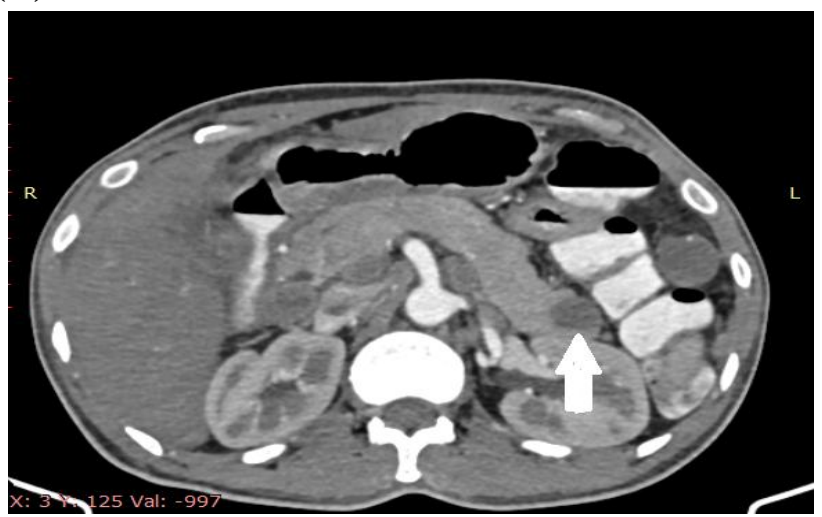

Fig 5 (A) Axial CT showing stomach mural involvement secondary to necrotic nodes and 5(B) Axial images in same patient show a non enhancing hypodense lesion (arrows) in tail of pancreas presumed to be tubercular affection. 


\section{Discussion}

The most common site involved in abdominal tuberculosis is the peritoneum followed by gastrointestinal tract, as seen in the present study $(\text { Table } 1)^{(3)}$. Peritoneal TB can be of three types- dry type, wet type and mass forming ${ }^{(4)}$. Classically, the more common 'wet' form demonstrates exudative peritoneal collection, and the 'dry' form is caused by fibrinous exudates and tubercles with widespread signs of peritoneal inflammation. Review of literature suggests CT findings of peritoneal tuberculosis include soft tissue density thickening with stranding of the mesentery and omentum, thickened bowel loops, high attenuation peritoneal collection and low density lymph nodes. ${ }^{(5,6)}$.

In our study most common type of peritoneal involvement was high attenuation peritoneal collection i.e. in 27 cases $(77.1 \%$ ) (Table 2). Out of this, smooth peritoneal thickening was found in 9 cases, nodular peritoneal thickening in 2 cases and omental caking in 4 cases.

Gastro-intestinal involvement of bowel loops occurs most commonly in the ileo-caecal site with circumferential thickening and regional lymphadenopathy, assumed to be due to abundance of lymphatic tissues and venous stasis at this site ${ }^{(7)}$. Later, ileocaecal valve involvement, gross asymmetric wall thickening, adherence of bowel loops and even a complex mass formation may be seen. In our study (Table 3), ileocaecal involvement was most common, i.e. in 8 out of 11 cases, involving bowel (Fig 2B). Symmetric thickening was slightly more common (6 cases) as compared to asymmetric thickening (5 cases); segmental (6$40 \mathrm{~cm}$ ) involvement being the most common longitudinal extent $(\text { Table } 4)^{(8)}$. Focal involvement (upto $5 \mathrm{~cm}$ in length) is more suggestive of neoplastic etiology and was seen in only one case of stomach tuberculosis. Loss of mural stratification was more common than preservation of the same (Table 5), the later favouring Crohn's disease according to most studies ${ }^{(6,9)}$. However, conflicting studies have been encountered ${ }^{(10)}$. Other findings favouring Crohn's are non necrotic lymph nodes, skip lesions, concomitant colonic and anorectal involvement, fistulas, etc. Mucosal hyper enhancement, although a nonspecific finding, is seen in active tuberculosis, as in more than half of our cases $^{(11)}$.

Isolated colonic, duodenal and gastric involvement is rare ${ }^{(12)}$. Concomitant gastric and pancreatic involvement secondary to necrotic abdominal nodal invasion was seen in 1 case (Fig 5). Ascending colon involvement was also seen in 1 case $(2.8 \%)$ only (Table 3), lower than that described in literature $^{(13)}$.

Sclerosing encapsulating peritonitis, formerly referred to as abdominal cocoon, can be classified as idiopathic and secondary. Idiopathic cause was first described by Foo et al in 1978 which primarily affects young females from tropical and subtropical countries $^{(14)}$. Secondary etiologies include chronic ambulatory peritoneal dialysis, ventriculo-peritoneal shunts, treatment with practolol, tuberculosis, sarcoidosis, protein $\mathrm{S}$ deficiency, etc. The classic findings of abdominal cocoon on CT scan consist of a thick fibrotic membrane causing total or partial encasement of the small intestine ${ }^{(15)}$. Two cases $(5.4 \%)$ of sclerosing encapsulating peritonitis were identified in our study (Fig 4).

Perforation and fistula are recognised complications, the small bowel and colon being the most common sites. However, in our study, this was present in only one case $(2.85 \%)$ (Table 6). Other complications include intussusception and small bowel obstruction, both of which were relatively more common in the present study $(\mathrm{Fig} 3 \mathrm{~A})^{(16)}$.

Mesenteric nodes are most common, enlarged usually, demonstrating central hypodensity consistent with necrosis (caseation) with occasional calcification $^{(17,18)}$. This correlated well with our study (Table 7), where lymphadenopathy was found in 16 cases $(45.7 \%)$ of which all were mesenteric. However, in our study homogenously enhancing nodes (10 cases) outnumbered necrotic nodes (1 case). Calcified nodes were found in 1 case only (2.8\%). As expected, pulmonary tuberculosis was the most common associated organ system involved (Table 8). 
This study had certain limitations. Firstly, the frequency of findings described were region specific. Certain investigations like Serum ADA, RT-PCR although expensive, don't have a specificity or sensitivity of $100 \%$. Involvement of bowel, spleen and pancreas were only confirmed by histopathological analysis of abdominal lymph nodes and not by direct biopsy of the organs.

\section{Conclusion}

The prevalence of tuberculosis in India remains high and hence, abdominal involvement of Mycobacteria must be seriously considered in our clinical setup. Though majority of imaging findings are nonspecific, radiological diagnosis of abdominal tuberculosis is possible only through corroboration of the CT findings with clinical and biochemical findings along with follow up, subsequent to a high degree of suspicion.

\section{References}

1. Paustian FF, Marshall JB. Bockus Gastroenterology. 4th ed. Philadelphia: WB Saunders; 1985. Intestinal tuberculosis. In: Berk JE, editor; pp. 2018-36.

2. M.P. Sharma, Vikram Bhatia. Abdominal tuberculosis. Indian J Med Res 120, October 2004, pp 305-315.

3. Sinan T, Sheikh M, Ramadan S, et al. CT features in abdominal tuberculosis: 20 years experience. BMC Med Imaging. 2002;2:3-3.

4. Hanson RD, Hunter TB. Tuberculous peritonitis: CT appearance. AJR Am J Roentgenol. 1985;144:931-932.

5. Zissin R, Gayer G, Chowers M, ShapiroFeinberg M, Kots E, Hertz M. Computerized tomography findings of abdominal tuberculosis: report of 19 cases. Isr Med Assoc J. 2001;3(6):414-8.

6. Sharma R, Madhusudhan KS, Ahuja V (2016) Intestinal tuberculosis versus Crohn's disease: clinical and radiological recommendations. Indian J Radiol Imaging. 26(2):161-172

7. Lundstedt C, Myman R, Brismar J, Hugosson C, Kagevi I. Imaging of tuberculosis II.
Abdominal manifestations in 112 patients. Acta Radiol. 1996;37:489-405

8. Macari M, Megibow AJ, Balthazar EJ. A pattern approach to the abnormal small bowel: observations at MDCT and CT enterography. AJR Am J Roentgenol. 2007;188:1344-1355.

9. Almadi MA, Ghosh S, Aljebreen AM. Differentiating intestinal tuberculosis from Crohn's disease: A diagnostic challenge. Am J Gastroenterol 2009;104:100312.

10. Zhao XS, Wang ZT, Wu ZY, Yin QH, Zhong J, Miao F, et al. Differentiation of Crohn's disease from intestinal tuberculosis by clinical and CT enterographic models. Inflamm Bowel Dis 2014;20:915-25.

11. Fernandes, T., Oliveira, M.I., Castro, R. et al. Bowel wall thickening at CT: simplifying the diagnosis. Insights Imaging 5, 195-208 (2014)

12. Lin OS, Wu SS, Yeh KT, Soon MS. Isolated gastric tuberculosis of the cardia. J Gastroenterol Hepatol. 1999;14:258-261.

13. Chawla S, Mukerjee P, Bery K. Segmental tuberculosis of the colon: A report of ten cases. ClinRadiol1971;22:104-9.

14. Foo KT, Ng KC, Rauff A, Foong WC, Sinniah R. Unusual small intestinal obstruction in adolescent girls: the abdominal cocoon. $\mathrm{Br} \mathrm{J}$ Surg. 1978;65:427-430.

15. Xu p, Chen LH, Li YM. Idiopathic scleroting encapsulating peritonitis (or abdominal cocoon): A report of 5 Cases. World J Gastroenterol. 2007;13(26):3649-3651.

16. Nagi B, Lal A, Kochhar R, et al. Perforations and fistulae in gastrointestinal tuberculosis. Acta Radiol.2002;43:501-506.

17. Epstein BM, Mann JH. CT of abdominal tuberculosis. AJR Am J Roentgenol. 1982; 139:861-6.

18. Kalra N, Agrawal P, Mittal V, Kochhar R, Gupta V, Nada R, et al. Spectrum of imaging findings on MDCT enterography in patients with small bowel tuberculosis. ClinRadiol 2014;69:315-22. 